\title{
Effect of high doses of folic acid supplementation in early pregnancy on child neurodevelopment at 18 months of age: the mother-child cohort 'Rhea' study in Crete, Greece
}

\author{
Leda Chatzi ${ }^{1, *}$, Eleni Papadopoulou $2,3,4,5$, Katerina Koutra ${ }^{1}$, Theano Roumeliotaki ${ }^{1}$, \\ Vaggelis Georgiou', Nikolaos Stratakis ${ }^{1}$, Vassiliki Lebentakou ', Mariana Karachaliou', \\ Maria Vassilaki ${ }^{1}$ and Manolis Kogevinas ${ }^{2,3,5}$ \\ 'Department of Social Medicine, Faculty of Medicine, University of Crete, PO Box 2208, 71003 Heraklion, \\ Crete, Greece: ${ }^{2}$ Centre for Research in Environmental Epidemiology (CREAL), Barcelona, Spain: ${ }^{3}$ Municipal \\ Institute of Medical Research (IMIM-Hospital del Mar), Barcelona, Spain: ${ }^{4}$ Department of Experimental and \\ Health Sciences, Pompeu Fabra University (UPF), Barcelona, Spain: ${ }^{5}$ National School of Public Health, \\ Athens, Greece
}

Submitted 14 July 2011: Accepted 20 December 2011: First published online 8 February 2012

\begin{abstract}
Objective: To investigate whether high doses of folic acid supplementation in early pregnancy are associated with child neurodevelopment at 18 months of age. Design: The study uses data from the prospective mother-child cohort 'Rhea' study. Pregnant women completed an interviewer-administered questionnaire on folic acid supplementation at 14-18 weeks of gestation. Neurodevelopment at 18 months was assessed with the use of the Bayley Scales of Infant and Toddler Development (3rd edition). Red-blood-cell folate concentrations in cord blood were measured in a sub-sample of the study population $(n 58)$.

Setting: Heraklion, Crete, Greece, 2007-2010.

Subjects: Five hundred and fifty-three mother-child pairs participating in the 'Rhea' cohort.

Results: Sixty-eight per cent of the study participants reported high doses of supplemental folic acid use $(5 \mathrm{mg} / \mathrm{d})$, while $24 \%$ reported excessive doses of folic acid $(>5 \mathrm{mg} / \mathrm{d})$ in early pregnancy. Compared with non-users, daily intake of $5 \mathrm{mg}$ supplemental folic acid was associated with a 5-unit increase on the scale of receptive communication and a 3.5-unit increase on the scale of expressive communication. Doses of folic acid supplementation higher than $5 \mathrm{mg} / \mathrm{d}$ were not associated with additional increase in the neurodevelopmental scales.

Conclusions: This is the first prospective study showing that high doses of supplementary folic acid in early pregnancy may be associated with enhanced vocabulary development, communicational skills and verbal comprehension at 18 months of age. Additional longitudinal studies and trials are needed to confirm these results.
\end{abstract}

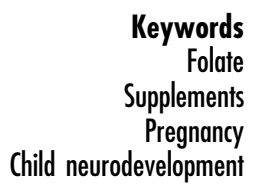

eywords

splements

Pregnancy

Child neurodevelopment
Adverse environmental events during sensitive periods of organ development trigger plastic responses that result in long-lasting functional alterations and influence risk for disease later in life ${ }^{(1)}$. Folic acid is an important micronutrient, essential for brain development and function in the antenatal and early postnatal periods ${ }^{(2,3)}$. Experimental data have shown that there is active placental transport of folic acid and that brain folic acid levels are elevated in the fetus during early development ${ }^{(4)}$. Folic acid intake is significantly correlated with circulating folic acid concentrations while during pregnancy large amounts of folic acid are required, thus there is a substantial risk of deficiency ${ }^{(5)}$. A deficiency in folic acid during pregnancy is a well-known risk factor for neural tube defects ${ }^{(6,7)}$. Moreover, animal studies have shown that folic acid plays an important role in early brain development as it influences neuronal and glial growth and proliferation, and can affect the synthesis and release of neurotransmitters such as dopamine, adrenaline and $\operatorname{serotonin}^{(4,8)}$.

There are few epidemiological studies demonstrating the impact of folic acid supplement use by healthy pregnant women on neurodevelopmental outcomes in their offspring and findings are not consistent. Four studies have shown a positive association of maternal folic acid status or folic acid supplement use on mental 
and cognitive development of the child ${ }^{(9-13)}$. However, most of these studies have focused on the effect of folic acid supplement use on child neurodevelopment at school ages and only one study has evaluated the effect of folic acid supplement use in early childhood (18 months of life $)^{(10)}$. Two other studies among healthy pregnant women did not find any association between folic acid supplement use in pregnancy and their children's neurodevelopment from 2 to 6 years of age ${ }^{(14,15)}$. Thus, despite the fact that early pregnancy is the most important period for embryogenesis and fetal programming, relatively little is known about the implications of low, moderate and high doses of folic acid supplementation during this particular pregnancy period on child neurodevelopment.

We examined whether high daily doses of folic acid supplementation in early pregnancy affect children's mental and psychomotor development at 18 months in the mother-child cohort 'Rhea' study in Crete, Greece.

\section{Materials and methods}

\section{Study population}

The 'Rhea' project is a mother-child study which examines prospectively a population-based cohort of pregnant women and their children at the prefecture of Heraklion in Crete, Greece ${ }^{(16)}$. Female residents (Greek and immigrants) who became pregnant during the 12 -month period starting February 2007 were contacted at four maternity clinics in Heraklion and asked to participate in the study. The first contact was made at the time of the first major ultrasound examination. Women were then contacted at mid pregnancy, at third trimester, at birth, at 6 and 18 after delivery, and they are currently being contacted at 4 years after birth. Interview-administered and medical records were used to obtain information on sociodemographic, environmental and psychosocial factors during pregnancy and early childhood. The study was conducted according to the guidelines laid down in the Declaration of Helsinki, and all procedures involving human subjects were approved by the ethical committee of the University Hospital in Heraklion, Crete, Greece. Written informed consent was obtained from all women participating in the study.

During the study recruitment period 1765 eligible women were approached; 1610 (91\%) agreed to participate and 1388 (86\%) were followed up until delivery. Detailed characteristics of the study population have been described elsewhere ${ }^{(16)}$. A random sample of 828 mothers were contacted by telephone at the 18 months follow-up and $599(72 \%)$ agreed to participate in the neurodevelopmental assessment ${ }^{(17)}$. Thirteen women (2\%) did not provide complete information on supplement use during pregnancy and therefore were excluded from the present analysis. We included only women with singleton pregnancies; thus multiple pregnancies were excluded ( $n$ 26). We also excluded seven infants due to incomplete examination $(n 1)$, signs of Pervasive Developmental Disorders $(n 1)$, plagiocephalus ( $n 1)$, brain tumour $(n 1)$, microcephalus ( $n$ 2) and hydrocephalus ( $n$ 1). Hence, a cohort of 553 ( $92 \%$ of the study population of children with neurodevelopment assessment) mother-child pairs was available for the present analysis (Fig. 1).

\section{Folic acid supplement use}

Pregnant women participating in the 'Rhea' study were asked, using a questionnaire administered by a trained research nurse between the 14th and 18th week of gestation, whether they had taken folic acid supplements since they became pregnant. Supplement users were asked to report the brand name, the dose and the frequency of intake. The answers were open and not pre-coded so as to ensure that all sources of supplementation were recorded and none was excluded. Supplement use (brand, dose, frequency) was converted into daily intake $(\mathrm{mg} / \mathrm{d}$ ) by using dosage information provided on the package of each product. The majority of women ( $n$ 492, 97\%) used only one product providing $5 \mathrm{mg}$ of folic acid per daily dose. None of the women who reported folic acid supplement use during early pregnancy ( $n$ 507) used multivitamins containing folic acid as well, while fourteen (2.8\%) of them used multivitamin products without folic acid. A small proportion of women $(n 72,14 \%)$ reported the use of both folic acid supplements and iron supplement products containing small amounts of folic acid; in these cases, the total quantity of folic acid was estimated by summing up all sources of daily intake. Folic acid supplement users were assigned to the following categories: (i) women with no folic acid intake from supplements $(0 \mathrm{mg} / \mathrm{d})$; (ii) those with daily intake of $5 \mathrm{mg}$ of folic acid from supplements $(5 \mathrm{mg} / \mathrm{d})$; and (iii) women with daily intake of folic acid from supplements higher than $5 \mathrm{mg}$, ranging from 6 to $15 \mathrm{mg} / \mathrm{d}(>5 \mathrm{mg} / \mathrm{d})$. There were no women with daily intake of supplemental folic acid between 0 and $4 \mathrm{mg}$.

\section{Validation of supplemental folic acid use}

Red-blood-cell folate concentrations in cord blood were measured by immunoassay with chemiluminescence (Roche kit, Elecsys 2010 analyser) in an effort to validate the self-reported folic acid supplement use. This analysis was available for a random sub-sample ( $n 58)$ of the total 'Rhea' study population. The collected cord blood samples were analysed in batches to reduce between-assay variability using an internal control (standard) for each batch. Mothers who reported supplemental folic acid use in early pregnancy ( $n 51 ; 88 \%$ ) gave birth to neonates with higher red-blood-cell folate concentrations in cord blood (mean $780 \mathrm{ng} / \mathrm{ml}$; range $402-1670 \mathrm{ng} / \mathrm{ml}$ ) compared with women $(n 7 ; 12 \%)$ who did not use folic acid supplements (mean $640 \mathrm{ng} / \mathrm{ml}$; range $358-1182 \mathrm{ng} / \mathrm{ml}$; $P=0.05$ from Mann-Whitney test for non-parametric comparisons between groups). 


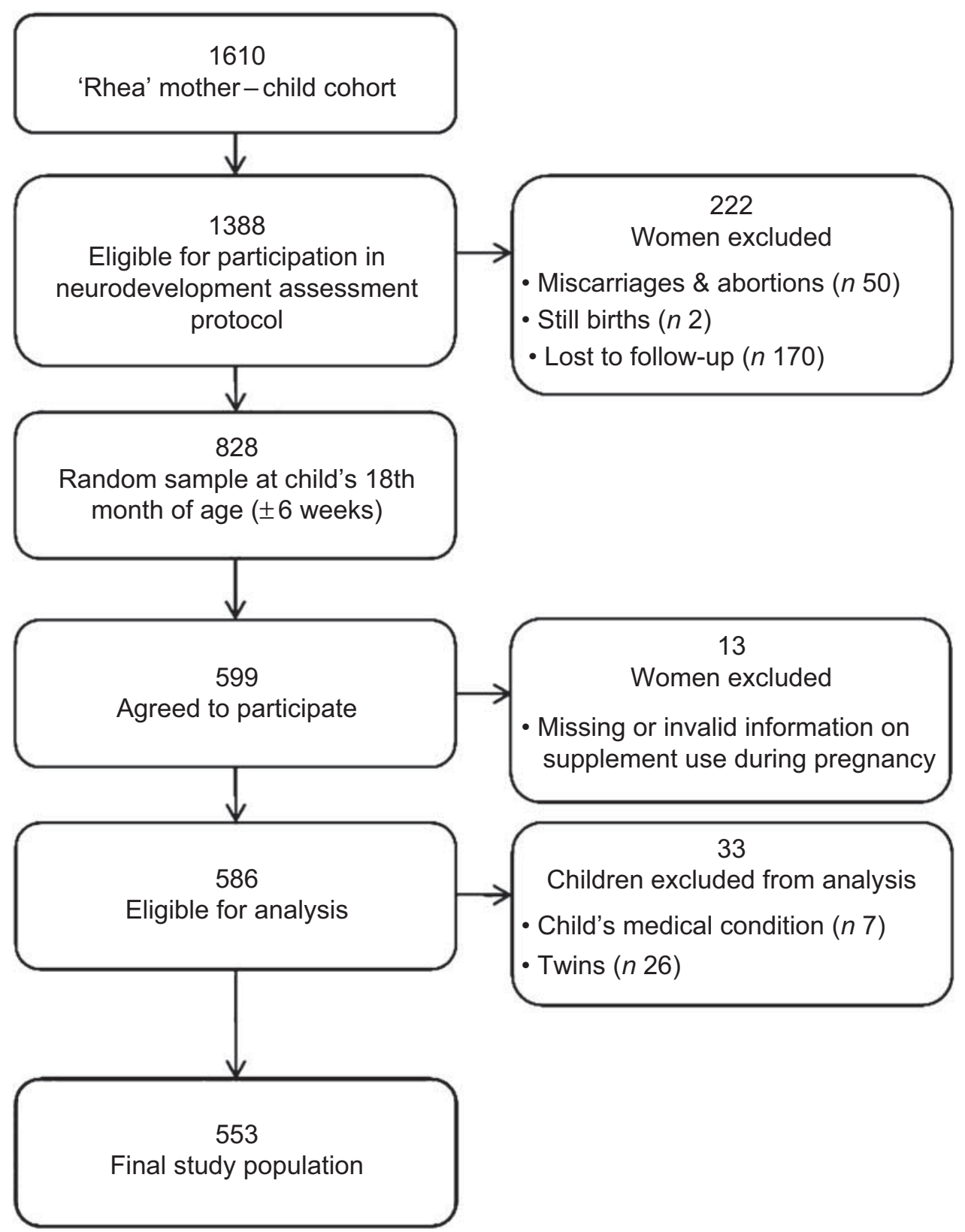

Fig. 1 Flow diagram defining the participants in the analysis

\section{Children's neurodevelopment}

The children's mental and psychomotor development was assessed at 18 months ( \pm 6 weeks) using the Bayley Scales of Infant and Toddler Development, 3rd edition (Bayley-III) ${ }^{(17)}$. The Bayley-III is an individually administered instrument that assesses the developmental functioning of infants and young children between 1 month and 42 months of age. Its primary purposes are to identify children with developmental delay and to provide information for intervention planning ${ }^{(18)}$.

The Bayley-III assesses infant and toddler development across three domains: (i) the Cognitive Scale (COG) include items that assess sensorimotor development, exploration and manipulation, object relatedness, concept formation, memory and other aspects of cognitive processing; (ii) the Language Scale is composed of the Receptive Communication (RC) and the Expressive Communication (EC) subtests. The RC subtest includes items that assess preverbal behaviours, vocabulary development, vocabulary related to morphological development and understanding of morphological markers, children's social referencing and verbal comprehension, while the EC subtest includes items that assess preverbal communication, vocabulary development and morpho-syntactic development; (iii) the Motor Scale is divided into the Fine Motor (FM) and the Gross Motor (GM) subtests. In the FM subtest are included fine motor skills associated with apprehension, perceptualmotor integration, motor planning and motor speed, while 
the GM subtest primarily measures movement of the limbs and torso.

We also used the self-reported Social-Emotional Scale (SE) of Bayley-III. This scale assesses the acquisition of social and emotional milestones in infants and young children that should be achieved by certain ages. It includes items that assess the child's mastery of functional emotional skills, communication needs, the child's ability to engage others and establish relationships, use emotions in an interactive, purposeful manner and use emotional signals or gestures to solve problems.

Neurodevelopmental assessments were conducted by three trained psychologists who completed a formal training course in the use, administration and interpretation of Bayley-III. All testing was done at the Medical School of the University of Crete, two public hospitals in Heraklion, always in the presence of the mother. Total administration time was approximately $90 \mathrm{~min}$.

The examiners also noted critical comments about the difficulties or special conditions of the neurodevelopmental assessment so as to evaluate the 'quality of assessment', such as no difficulties, infants participated in the reliability study, difficulties due to physical problems (e.g. physical illness, tiredness, asleep, etc.), or difficulties due to behaviour problems (e.g. nervous, shy, etc.).

For each scale, the child's score was determined by the number of items for which credit was received. We analysed raw scores instead of scaled scores and composite score equivalents because the US reference sample may not be appropriate for children outside the USA. Raw scores were standardised to a mean of 100 with a standard deviation of 15 to homogenise all scales.

Mothers were re-contacted by mail within a month of the assessment and given feedback on their child's performance at the test.

\section{Validation of neurodevelopmental assessment}

Twelve children participated in the reliability study of the neurodevelopmental assessment. Each of the psychologists conducted four interviews as examiner while the other two examiners were simultaneously scoring the Bayley-III tests for COG, RC, EC, FM and GM scales as observers, in order to achieve exchangeability. The intraclass correlation coefficient (ICC) was used to measure the inter-rater reliability for absolute agreement between scores in a two-way random model. The inter-rater reliabilities were as follows: $\operatorname{ICC}_{\mathrm{COG}}=0.990 \quad(P<0.001)$, $\mathrm{ICC}_{\mathrm{RC}}=0.996 \quad(P<0.001), \quad \mathrm{ICC}_{\mathrm{EC}}=0.994 \quad(P<0.001)$, $\mathrm{ICC}_{\mathrm{FM}}=0.924(P<0.001)$ and $\mathrm{ICC}_{\mathrm{GM}}=0.972(P<0.001)$.

\section{Potential confounders}

Potential confounders included characteristics that have an established or potential association with child neurodevelopment and use of folic acid supplements in pregnancy, including: maternal and paternal age; maternal and paternal education (low level, $\leq 6$ years of school; medium level, $\leq 12$ years of school; high level, university or technical college degree); maternal working status in the first year of life (yes/no); maternal pre-pregnancy BMI $\left(\mathrm{kg} / \mathrm{m}^{2}\right)$; maternal and paternal origin (Greek/other); marital status (married/other); maternal smoking during pregnancy (yes/ no); maternal alcohol intake during pregnancy $(\mathrm{g} / \mathrm{d})$; parity (primiparous; multiparous); type of delivery (Caesarean/ vaginal); infant gender (male/female); birth weight $(\mathrm{g})$; gestational age (weeks); preterm birth (yes/no); breastfeeding duration (months); day-care attendance (yes/no), parental smoking in the first year of life (yes/no); homeenvironment factors (number of people living in the house, number of bedrooms, cleaning practices, indoor domestic pets, presence of mould in the house).

\section{Statistical analysis}

Raw scores were standardised for psychologist and child's age at test administration using a parametric method for the estimation of age-specific reference intervals ${ }^{(19)}$. The parameters of the distribution were modelled as fractional polynomial functions of age and estimated by maximum likelihood. Standardised residuals were then typified having a mean of 100 points with a standard deviation of 15 to homogenise the scales (parameters conventionally used in psychometrics for assessing intelligence quotient).

Univariate associations between the child neurodevelopmental assessment, both raw and standardised scores, and supplement use during early pregnancy were assessed using the $\chi^{2}$ test for categorical variables, the independent $t$ test for continuous normally distributed variables and the Mann-Whitney $U$ test for continuous nonnormally distributed variables. Multivariable linear regression models were implemented to examine the associations between standardised scores and supplement use during pregnancy, after adjusting for several confounders. Separate multivariable models were built having as an outcome each one of the six neurodevelopmental scales (COG, RC, EC, FM, GM and SE). Potential confounders related with the outcomes of interest in the bivariate models at $P<0 \cdot 2$ were included in the multivariable models. Beta coefficients with 95\% confidence intervals in multivariable linear regression models were computed to estimate the degree of association between the exposure and the outcome of interest. The 'quality of assessment' and child's gender were treated as a priori confounders and were included in all multivariable regression models. All hypothesis testing was conducted assuming a 0.05 significance level and a twosided alternative hypothesis. All statistical analyses were performed using the statistical software package PASW Statistics 18 (SPSS Inc., Chicago, IL, USA).

\section{Results}

The majority of women participating in the present study were taking folic acid supplements ( $n$ 507, 91.7\%) in 
Table 1 Sociodemographic, medical and lifestyle characteristics according to folic acid supplement use in early pregnancy, the mother-child cohort 'Rhea' study, Crete, Greece ( $n$ 553)

\begin{tabular}{|c|c|c|c|c|c|c|c|}
\hline & \multicolumn{6}{|c|}{ Use of folic acid supplements } & \multirow[b]{3}{*}{$P+$} \\
\hline & \multicolumn{2}{|c|}{ None (n 46) } & \multicolumn{2}{|c|}{$5 \mathrm{mg} / \mathrm{d}(n 373)$} & \multicolumn{2}{|c|}{$>5 \mathrm{mg} / \mathrm{d}(n$ 134) } & \\
\hline & Mean or $n$ & SD or $\%$ & Mean or $n$ & SD or $\%$ & Mean or $n$ & SD or $\%$ & \\
\hline \multicolumn{8}{|l|}{ Maternal characteristics } \\
\hline Age at delivery (years) $\ddagger$ & $29 \cdot 9$ & $5 \cdot 7$ & $30 \cdot 3$ & $4 \cdot 5$ & $30 \cdot 3$ & $4 \cdot 4$ & 0.659 \\
\hline Maternal pre-pregnancy BMI $\left(\mathrm{kg} / \mathrm{m}^{2}\right) \ddagger$ & $24 \cdot 5$ & $4 \cdot 6$ & $24 \cdot 2$ & $4 \cdot 7$ & $24 \cdot 4$ & $5 \cdot 1$ & 0.570 \\
\hline \multicolumn{8}{|l|}{ Maternal education } \\
\hline Low ( $\leq 9$ years) & 11 & $25 \cdot 6$ & 44 & $11 \cdot 8$ & 13 & $9 \cdot 8$ & \multirow[t]{3}{*}{0.096} \\
\hline Medium ( $\leq 12$ years) & 18 & 41.9 & 184 & $49 \cdot 3$ & 68 & $51 \cdot 1$ & \\
\hline High ( $>13$ years) & 14 & $32 \cdot 6$ & 145 & $38 \cdot 9$ & 52 & $39 \cdot 1$ & \\
\hline \multicolumn{8}{|l|}{ Maternal origin } \\
\hline Greek & 43 & $93 \cdot 5$ & 363 & $97 \cdot 6$ & 127 & $94 \cdot 8$ & \multirow[t]{2}{*}{$0 \cdot 152$} \\
\hline Non-Greek & 3 & $6 \cdot 5$ & 9 & $2 \cdot 4$ & 7 & $5 \cdot 2$ & \\
\hline \multicolumn{8}{|l|}{ Marital status } \\
\hline Married & 35 & $81 \cdot 4$ & 344 & $92 \cdot 2$ & 117 & $87 \cdot 3$ & \multirow[t]{2}{*}{0.034} \\
\hline Other & 8 & $18 \cdot 6$ & 29 & $7 \cdot 8$ & 17 & $12 \cdot 7$ & \\
\hline \multicolumn{8}{|l|}{ Parity } \\
\hline Primiparous & 20 & $46 \cdot 5$ & 154 & $42 \cdot 2$ & 58 & $45 \cdot 3$ & \multirow[t]{2}{*}{0.750} \\
\hline Multiparous & 23 & $53 \cdot 5$ & 211 & $57 \cdot 8$ & 70 & $54 \cdot 7$ & \\
\hline \multicolumn{8}{|c|}{ Maternal working status at 18 months after delivery } \\
\hline Yes & 22 & $47 \cdot 8$ & 233 & $62 \cdot 6$ & 91 & $67 \cdot 9$ & \multirow[t]{2}{*}{0.052} \\
\hline No & 24 & $52 \cdot 2$ & 139 & $37 \cdot 4$ & 43 & $32 \cdot 1$ & \\
\hline \multicolumn{8}{|l|}{ Smoking status during pregnancy } \\
\hline Non-smoker & 23 & $53 \cdot 5$ & 213 & $57 \cdot 4$ & 80 & $59 \cdot 7$ & \multirow{3}{*}{0.529} \\
\hline Quit during pregnancy & 12 & $27 \cdot 9$ & 78 & $21 \cdot 0$ & 33 & $24 \cdot 6$ & \\
\hline Smoking during pregnancy & 8 & $18 \cdot 6$ & 80 & $21 \cdot 6$ & 21 & $15 \cdot 7$ & \\
\hline \multicolumn{8}{|l|}{ Alcohol intake during pregnancy } \\
\hline$\leq 2.5 \mathrm{~g} / \mathrm{d}$ & 9 & $50 \cdot 0$ & 182 & $72 \cdot 2$ & 77 & $72 \cdot 0$ & \multirow[t]{2}{*}{$0 \cdot 129$} \\
\hline$>2.5 \mathrm{~g} / \mathrm{d}$ & 9 & $50 \cdot 0$ & 70 & $27 \cdot 8$ & 30 & $28 \cdot 0$ & \\
\hline \multicolumn{8}{|l|}{ Child characteristics } \\
\hline Gestational age at delivery (weeks) $\ddagger$ & $37 \cdot 9$ & $1 \cdot 6$ & $38 \cdot 3$ & $1 \cdot 4$ & $38 \cdot 4$ & $1 \cdot 3$ & $0 \cdot 148$ \\
\hline Birth weight $(g) \ddagger$ & 3057 & $493 \cdot 7$ & 3198 & 448.9 & 3167 & $376 \cdot 5$ & $0 \cdot 120$ \\
\hline Breast-feeding duration (months) $\ddagger$ & $2 \cdot 8$ & $3 \cdot 0$ & $4 \cdot 4$ & 4.5 & $4 \cdot 6$ & $4 \cdot 2$ & 0.054 \\
\hline \multicolumn{8}{|l|}{ Infant gender } \\
\hline Male & 25 & $54 \cdot 3$ & 198 & $53 \cdot 1$ & 73 & $54 \cdot 5$ & \multirow[t]{2}{*}{0.956} \\
\hline Female & 21 & $45 \cdot 7$ & 175 & $46 \cdot 9$ & 61 & $45 \cdot 5$ & \\
\hline Type of delivery & & & & & & & \\
\hline Normal & 28 & $62 \cdot 2$ & 185 & $49 \cdot 6$ & 64 & $48 \cdot 1$ & 0.236 \\
\hline Caesarean & 17 & $37 \cdot 8$ & 188 & $50 \cdot 4$ & 69 & $51 \cdot 9$ & \\
\hline Preterm birth & & & & & & & \\
\hline Yes & 5 & $10 \cdot 9$ & 36 & $9 \cdot 7$ & 15 & $11 \cdot 2$ & 0.866 \\
\hline No & 41 & $89 \cdot 1$ & 337 & $90 \cdot 3$ & 119 & $88 \cdot 8$ & \\
\hline Day-care attendance & & & & & & & \\
\hline Yes & 0 & 0.0 & 39 & $10 \cdot 5$ & 9 & $6 \cdot 7$ & 0.037 \\
\hline No & 46 & $100 \cdot 0$ & 332 & $89 \cdot 5$ & 125 & $93 \cdot 3$ & \\
\hline
\end{tabular}

$+P$ value from Pearson's $\chi^{2}$ test for categorical variables and the Kruskal-Wallis test or ANOVA for continuous variables, for comparison between non-users and users of folic acid at a dose of $5 \mathrm{mg} / \mathrm{d}$ and $>5 \mathrm{mg} / \mathrm{d}$.

$\ddagger$ Values are presented as mean and standard deviation.

early pregnancy. Sociodemographic, medical and lifestyle characteristics of the 553 mother-child pairs according to the use of folic acid supplements are presented in Table 1. Pregnant women who used folic acid supplements were more likely to be highly educated, married and working after birth. The children of women who used folic acid supplements in early pregnancy had longer duration of breast-feeding and were more likely to attend day care compared with children of mothers who did not use folic acid supplements.

Sixty-eight per cent of women ( $n$ 373) reported daily intake of $5 \mathrm{mg}$ folic acid from supplements $(5 \mathrm{mg} / \mathrm{d})$, while $24 \%$ ( $n$ 134) reported higher doses of folic acid $(>5 \mathrm{mg} / \mathrm{d})$, and $8 \%(n 46)$ reported no use of folic acid supplements in early pregnancy. Women with daily folic acid intakes of $5 \mathrm{mg}$ were more likely to take one daily dose of supplemental folic acid, while women with higher intakes reported more than one daily dose.

Table 2 shows the unadjusted and adjusted associations between supplementary folic acid use in early pregnancy and child neurodevelopment at 18 months of age. In the univariate analysis, daily intake of $5 \mathrm{mg}$ folic acid from supplements was associated with increases of 5.4 units in the scale of receptive communication, $4 \cdot 2$ units in the scale of expressive communication and 4.7 units in the scale of fine motor development. After adjustment for maternal age, education, parity, breast-feeding duration, day-care attendance, birth weight, infant gender and 
Table 2 Association between folic acid intake from supplements in early pregnancy and child neurodevelopment at 18 months of age ( $n$ 553), the mother-child cohort 'Rhea' study, Crete, Greece

\begin{tabular}{|c|c|c|c|c|c|c|c|c|}
\hline \multirow[b]{4}{*}{ Standardised scores on Bayley-III scales } & \multicolumn{8}{|c|}{ Supplementary folic acid intake } \\
\hline & \multicolumn{4}{|c|}{$5 \mathrm{mg} / \mathrm{d}$} & \multicolumn{4}{|c|}{$>5 \mathrm{mg} / \mathrm{d}$} \\
\hline & \multicolumn{2}{|c|}{ Unadjustedt } & \multicolumn{2}{|c|}{ Adjusted $\ddagger$} & \multicolumn{2}{|c|}{ Unadjustedt } & \multicolumn{2}{|c|}{ Adjusted $\ddagger$} \\
\hline & $\beta$ & $95 \% \mathrm{Cl}$ & $\beta$ & $95 \% \mathrm{Cl}$ & $\beta$ & $95 \% \mathrm{Cl}$ & $\beta$ & $95 \% \mathrm{Cl}$ \\
\hline Cognitive & $1 \cdot 2$ & $-3 \cdot 2,5 \cdot 6$ & $0 \cdot 1$ & $-4 \cdot 3,4 \cdot 6$ & $1 \cdot 2$ & $-3 \cdot 6,6 \cdot 0$ & $0 \cdot 3$ & $-4 \cdot 5,5 \cdot 2$ \\
\hline \multicolumn{9}{|l|}{ Communicational } \\
\hline Receptive & $5 \cdot 4^{*}$ & $1 \cdot 2,9 \cdot 7$ & $4 \cdot 7^{*}$ & $0 \cdot 5,8 \cdot 5$ & $5 \cdot 0^{*}$ & $0 \cdot 4,9 \cdot 6$ & $3 \cdot 9$ & $-0 \cdot 7,8 \cdot 5$ \\
\hline Expressive & $4 \cdot 2^{*}$ & $1 \cdot 1,9 \cdot 2$ & $3 \cdot 5^{\star}$ & $0 \cdot 6,7 \cdot 9$ & $5 \cdot 0^{*}$ & $0 \cdot 2,9 \cdot 8$ & $4 \cdot 0$ & $-0 \cdot 8,8 \cdot 7$ \\
\hline \multicolumn{9}{|l|}{ Motor } \\
\hline Fine & $4 \cdot 7^{\star}$ & $0 \cdot 3,9 \cdot 0$ & $2 \cdot 6$ & $-2 \cdot 0,7 \cdot 1$ & $3 \cdot 1$ & $-1 \cdot 7,7 \cdot 9$ & $1 \cdot 0$ & $-4 \cdot 0,5 \cdot 9$ \\
\hline Gross & $3 \cdot 0$ & $-1 \cdot 5,7 \cdot 5$ & $2 \cdot 5$ & $-2 \cdot 3,7 \cdot 2$ & $2 \cdot 8$ & $-2 \cdot 1,7 \cdot 8$ & $1 \cdot 9$ & $-3 \cdot 2,7 \cdot 1$ \\
\hline Social-Emotional & $-1 \cdot 8$ & $-6 \cdot 4,2 \cdot 9$ & $-2 \cdot 8$ & $-7 \cdot 7,2 \cdot 0$ & -0.4 & $-5 \cdot 4,4 \cdot 7$ & $-1 \cdot 4$ & $-6 \cdot 7,3 \cdot 9$ \\
\hline
\end{tabular}

Bayely-III, Bayley Scales of Infant and Toddler Development, 3rd edition.

${ }^{\star}$ Coefficient was significant at $P<0.05$.

$+\beta$ and $95 \% \mathrm{Cl}$ are estimated using linear regression models adjusting for quality of assessment and child gender. Reference category is women who did not use folic acid supplements in pregnancy.

$\ddagger \beta$ and $95 \% \mathrm{Cl}$ are estimated using linear regression models adjusting for maternal age, education, parity, breast-feeding duration, day-care attendance, birth weight, infant gender and quality of assessment. Reference category is women who did not use folic acid supplements in pregnancy.

Table 3 The association between folic acid intake from supplements in early pregnancy and child neurodevelopment at 18 months of age, after excluding preterm births ( $n 56$ ), the mother-child cohort 'Rhea' study, Crete, Greece

\begin{tabular}{|c|c|c|c|c|c|c|c|c|}
\hline \multirow[b]{4}{*}{ Standardised scores on Bayley-III scales } & \multicolumn{8}{|c|}{ Supplementary folic acid intake } \\
\hline & \multicolumn{4}{|c|}{$5 \mathrm{mg} / \mathrm{d}$} & \multicolumn{4}{|c|}{$>5 \mathrm{mg} / \mathrm{d}$} \\
\hline & \multicolumn{2}{|c|}{ Unadjustedt } & \multicolumn{2}{|c|}{ Adjusted $\ddagger$} & \multicolumn{2}{|c|}{ Unadjustedt } & \multicolumn{2}{|c|}{ Adjusted $\ddagger$} \\
\hline & $\beta$ & $95 \% \mathrm{Cl}$ & $\beta$ & $95 \% \mathrm{Cl}$ & $\beta$ & $95 \% \mathrm{Cl}$ & $\beta$ & $95 \% \mathrm{Cl}$ \\
\hline $\begin{array}{l}\text { Cognitive } \\
\text { Communicational }\end{array}$ & $1 \cdot 5$ & $-3 \cdot 1,6 \cdot 2$ & 0.6 & $-4 \cdot 1,5 \cdot 3$ & $1 \cdot 5$ & $-3 \cdot 5,6 \cdot 6$ & $0 \cdot 7$ & $-4 \cdot 5,5 \cdot 8$ \\
\hline $\begin{array}{l}\text { Receptive } \\
\text { Expressive }\end{array}$ & $\begin{array}{l}6 \cdot 0^{*} \\
5 \cdot 0^{*}\end{array}$ & $\begin{array}{l}1 \cdot 6,10 \cdot 5 \\
0 \cdot 3,9 \cdot 7\end{array}$ & $\begin{array}{l}5 \cdot 5^{\star} \\
4 \cdot 5^{\star}\end{array}$ & $\begin{array}{l}1 \cdot 1,10 \cdot 0 \\
0 \cdot 2,9 \cdot 1\end{array}$ & $\begin{array}{l}6 \cdot 0^{*} \\
5 \cdot 6^{*}\end{array}$ & $\begin{array}{l}1 \cdot 1,10 \cdot 8 \\
0 \cdot 4,10 \cdot 7\end{array}$ & $\begin{array}{l}5 \cdot 0 \\
4 \cdot 7\end{array}$ & $\begin{array}{r}0.1,9 \cdot 8 \\
-0.4,9 \cdot 8\end{array}$ \\
\hline Motor & & & & & & & & \\
\hline $\begin{array}{l}\text { Fine } \\
\text { Gross } \\
\text { Social-Emotional }\end{array}$ & $\begin{array}{r}4 \cdot 6 \\
2 \cdot 3 \\
-1 \cdot 8\end{array}$ & $\begin{array}{l}-0 \cdot 1,9 \cdot 3 \\
-5 \cdot 5,7 \cdot 1 \\
-6 \cdot 7,3 \cdot 1\end{array}$ & $\begin{array}{r}2 \cdot 3 \\
1 \cdot 4 \\
-3 \cdot 0\end{array}$ & $\begin{array}{l}-2 \cdot 6,7 \cdot 1 \\
-3 \cdot 7,6 \cdot 4 \\
-8 \cdot 2,2 \cdot 2\end{array}$ & $\begin{array}{r}2 \cdot 7 \\
1 \cdot 9 \\
-0 \cdot 7\end{array}$ & $\begin{array}{l}-2 \cdot 3,7 \cdot 9 \\
-3 \cdot 3,7 \cdot 1 \\
-6 \cdot 1,4 \cdot 6\end{array}$ & $\begin{array}{r}0 \cdot 4 \\
0 \cdot 4 \\
-1 \cdot 7\end{array}$ & $\begin{array}{l}-4 \cdot 9,5 \cdot 7 \\
-5 \cdot 1,6 \cdot 0 \\
-7 \cdot 4,4 \cdot 0\end{array}$ \\
\hline
\end{tabular}

Bayely-III, Bayley Scales of Infant and Toddler Development, 3rd edition.

${ }^{*}$ Coefficient was significant at $P<0.05$.

$+\beta$ and $95 \% \mathrm{Cl}$ are estimated using linear regression models adjusting for quality of assessment and child gender. Reference category is women who did not use folic acid supplements in pregnancy.

$\ddagger \beta$ and $95 \% \mathrm{Cl}$ are estimated using linear regression models adjusting for maternal age, education, parity, breast-feeding duration, day-care attendance, birth weight, infant gender and quality of assessment. Reference category is women who did not use folic acid supplements in pregnancy.

quality of assessment, significant associations remained only for receptive communication and expressive communication. Daily intakes of supplemental folic acid higher than $5 \mathrm{mg}$ were not associated with additional increase in the mental and psychomotor scores.

To test the possibility of confounding by prematurity we performed additional analyses excluding all preterm births ( $n$ 56, 10\%), and results remained similar to the original analysis (Table 3).

\section{Discussion}

In the prospective, population-based 'Rhea' mother-child cohort study we showed that daily intakes of $5 \mathrm{mg}$ supplemental folic acid in early pregnancy were associated with improvement in offspring's receptive and expressive communication skills at 18 months of age. No additional improvement was observed with excessive doses of folic acid supplementation.

These results are in accordance with two other birth cohort studies in The Netherlands and Spain evaluating the effect of folic supplementation in the first trimester of pregnancy on children's neurodevelopment, which showed positive associations with behavioural development at 18 months of age ${ }^{(10)}$ and verbal and verbal-executive function abilities at 4 years of age ${ }^{(9)}$, respectively. In contrast to these findings, another longitudinal study assessing folic acid status late in pregnancy found no significant associations with children's neurodevelopment at 5 years of age ${ }^{(15)}$. This discrepancy may be explained by the time of measuring exposure and the follow-up of a non-population-based 
sample of educationally and environmentally deprived women in the latter study.

Animal studies have linked increased cognitive performance with folic acid intake during pregnancy ${ }^{(20)}$, while others have focused on the adverse neurochemical and behavioural effects of folate restriction during gestation $^{(21-23)}$. Findings in folate-deficient rodents include ultrastructural abnormalities in rat brain capillaries ${ }^{(24)}$ and slowed neurogenesis in mouse brain ${ }^{(25)}$.

Folic acid is critically important for fetal development as it is required for cell division because of its role in DNA synthesis ${ }^{(26)}$. It acts also as a cofactor for many essential cellular reactions including the transfer of single-carbon units, and it is a substrate for a variety of reactions that affect the metabolism of several amino acids, including the transmethylation and transsulfuration pathways ${ }^{(27)}$. Folic acid is important in neurogenesis, in cell growth and proliferation, and in myelination ${ }^{(4)}$. Craciunescu et al. have shown that dietary folic acid availability affects mouse brain development, especially the neocortex which is the part of the brain responsible for complex behaviours such as cognition, attention and social competence, long after neural tube closure by influencing cell mitosis and apoptosis in the brain ${ }^{(8)}$. Additionally, folic acid is involved in processes of the synthesis of dopamine and serotonin, neurotransmitters that affect behavioural and cognitive functions $^{(28)}$.

A rising body of evidence suggests epigenetic modification as a plausible mechanism that leads to neuropsychiatric conditions ${ }^{(29)}$. It has been hypothesised that aberrant DNA methylation might be implicated within the aetiology of psychotic disorders through abnormal neurodevelopment ${ }^{(30,31)}$. The fidelity of DNA methylation patterns crucially depends on the regulation of the folate and one-carbon cycle ${ }^{(32)}$ and folate is critically involved in processes of methylation and hydroxylation which appear to be of particular importance for neurotransmission. Thus, the pathways underlying the association between folic acid and brain development involve several genetic, biochemical and biological factors.

An important finding in the present analysis is that all women had daily intakes of folic acid from supplements higher than the tolerable upper intake level for adults $(1 \mathrm{mg} / \mathrm{d})$, while no additional protection was observed with doses of folic acid supplementation higher than $5 \mathrm{mg} / \mathrm{d}$. This high dose is mainly due to the fact that the majority of women ( $n$ 1096, $85 \cdot 7 \%$ ) used only one product providing $5 \mathrm{mg}$ of folic acid per dose. This specific product is distributed in Greece and Malta and contains $5 \mathrm{mg}$ of folic acid per tablet. Similarly, a previous study in Greece examining the total intake of micronutrients in pregnant women in Greece revealed that the total intake of folate was about $3000 \mu \mathrm{g} / \mathrm{d}^{(33)}$. These intakes are extremely high compared with the estimates from other European countries ${ }^{(34,35)}$. Although folic acid fortification has been successful in reducing the incidence of neural tube defects ${ }^{(36,37)}$, the consequences of long-term high folate intake are not known. High doses of folic acid supplementation have been associated with the presence of plasma unmetabolised folic acid ${ }^{(38)}$ and recent studies have linked high folate intake and increased plasma concentrations to a number of adverse effects ${ }^{(39-43)}$. Moreover, excessive folic acid intake ( $15 \mathrm{mg} / \mathrm{d})$ has been associated with behavioural changes such as irritability, over-activity and altered sleep patterns in volunteer subjects $^{(4)}$. Because of the potential epigenetic effects of folic acid supplementation on the genome of the offspring, further studies are needed to investigate the effects of prenatal high doses of supplemental folic acid in children's mental and psychomotor development.

Strengths of the present study include the populationbased prospective design and the high participation rate $(90 \%)$. The Bayley-III that was used for the neurodevelopmental assessment of children is recognised internationally as one of the most comprehensive tools to assess children starting as young as 1 month old, identify infant and toddler strengths and competencies, as well as their weaknesses, and provide a valid and reliable measure of a child's mental and psychomotor abilities ${ }^{(44)}$. The exclusion of women who gave birth to twins as well as the adjustment for several sociodemographic variables reduced the likelihood of confounding. The study population included women from the follow-up of a birth cohort, providing the opportunity to account for the effect of exposures during pregnancy prospectively within the cohort. We did not observe any substantial differences between the crude and the adjusted models. Thus, it is unlikely that over-adjustment affected our findings. Participants were unaware of the hypothesis being tested, so misclassification of folic acid supplement intake estimated by the questionnaire is likely to be random with respect to neurodevelopmental outcomes.

There are several limitations in the present study that deserve acknowledgement. We could not distinguish between mothers who took supplements preconceptionally from those who started once pregnancy was detected. The use of questionnaires to assess micronutrient supplementation may have led to the misclassification of exposure, despite the clear question concerning supplements. However, the validation study showed good level of agreement between the estimates from the questionnaire and redblood-cell folate concentrations in cord blood samples. Unfortunately, we were not able to perform multivariable linear regression analysis with red-blood-cell folate levels and neurodevelopmental outcome parameters due to small numbers. We aimed to assess folic acid supplementation in early pregnancy to minimise possible recall bias, although we had no information on the duration of folic acid supplementation. The majority of women used folic acid supplements alone or in combination with iron, while a very small proportion of mothers reported the use of multivitamins in early pregnancy. Consequently, the possibility of 
confounding by intake of other macro- and micronutrients that could affect folate metabolism is minimised. Finally, use of supplements in pregnancy is related to socio-economic status, lifestyle factors (dietary habits) and adverse health behaviours (smoking). Although we incorporated extensive information on potential social and environmental factors that are associated with children's neurodevelopment, residual confounding cannot be excluded. For example, maternal intellectual ability, children's nutritional status at the time of testing, postnatal data on multivitamin use and growth curves of the children up to the postnatal study moment may well serve as additional confounding factors. Although the information on children's dietary intake as well as postnatal growth data were collected within the 'Rhea' cohort, the data are not available yet for analysis.

\section{Conclusions}

The present study suggests that high doses of folic acid supplementation in early pregnancy may be associated with enhanced vocabulary development, communicational skills and verbal comprehension at 18 months of age. Future longitudinal studies are needed to confirm these findings, better understand the complex underlying processes and examine the effect of high doses of folic acid supplements during pregnancy on neurodevelopmental disorders such as attention deficit hyperactivity disorder and autism in later childhood.

\section{Acknowledgements}

This work was partly supported by the EU Integrated Projects ENVIROGENOMARKERS (7th Framework Programme, Contract no. FP7-ENV-2008-226756) and CHICOS (7th Framework Programme, Contract no. Health-F2-2009241604). The authors declare no conflict of interest. All authors made a substantial contribution to the study and they have all personally reviewed and approved the submitted manuscript. Specifically: L.C. conceived the study, conducted the data analysis and prepared the manuscript; E.P. contributed to the design of the study and the drafting of the manuscript; K.K. implemented the measures of neurodevelopment used in the study, reviewed and provided key input to the manuscript; T.R. and V.G. carried out the statistical analysis and helped with the data interpretation and manuscript preparation; N.S., V.L., M. Karachaliou and M.V. supervised the data collection and helped with the analysis of supplements and manuscript preparation; M. Kogevinas supervised the data collection, provided critical review of the manuscript and helped with data interpretation and manuscript preparation. The authors would particularly like to thank all of the cohort participants for their generous collaboration.

\section{References}

1. Gluckman PD, Hanson MA \& Beedle AS (2007) Early life events and their consequences for later disease: a life history and evolutionary perspective. Am J Hum Biol 19, $1-19$.

2. Benton D (2008) Micronutrient status, cognition and behavioral problems in childhood. Eur J Nutr 47, Suppl. 3, 38-50.

3. Black MM (2008) Effects of vitamin $B_{12}$ and folate deficiency on brain development in children. Food Nutr Bull 29, 2 Suppl., S126-S131.

4. Greenblatt JM, Huffman LC \& Reiss AL (1994) Folic acid in neurodevelopment and child psychiatry. Prog Neuropsychopharmacol Biol Psychiatry 18, 647-660.

5. Scholl TO \& Johnson WG (2000) Folic acid: influence on the outcome of pregnancy. Am J Clin Nutr 71, 5 Suppl., 1295S-1303S

6. Lumley J, Watson L, Watson M et al. (2001) Periconceptional supplementation with folate and/or multivitamins for preventing neural tube defects. Cochrane Database Syst Rev issue 3, CD001056.

7. Lee JI, Lee JA \& Lim HS (2005) Effect of time of initiation and dose of prenatal iron and folic acid supplementation on iron and folate nutriture of Korean women during pregnancy. Am J Clin Nutr 82, 843-849.

8. Craciunescu CN, Brown EC, Mar MH et al. (2004) Folic acid deficiency during late gestation decreases progenitor cell proliferation and increases apoptosis in fetal mouse brain. J Nutr 134, 162-166.

9. Julvez J, Fortuny J, Mendez M et al. (2009) Maternal use of folic acid supplements during pregnancy and four-year-old neurodevelopment in a population-based birth cohort. Paediatr Perinat Epidemiol 23, 199-206.

10. Roza SJ, van Batenburg-Eddes T, Steegers EAP et al. (2010) Maternal folic acid supplement use in early pregnancy and child behavioural problems: The Generation R Study. BrJ Nutr 103, 445-452.

11. Schlotz W, Jones A, Phillips DIW et al. (2010) Lower maternal folate status in early pregnancy is associated with childhood hyperactivity and peer problems in offspring. J Child Psychol Psychiatry 51, 594-602.

12. Veena SR, Krishnaveni GV, Srinivasan K et al. (2010) Higher maternal plasma folate but not vitamin B-12 concentrations during pregnancy are associated with better cognitive function scores in 9- to 10-year-old children in South India. J Nutr 140, 1014-1022.

13. Wehby GL \& Murray JC (2008) The effects of prenatal use of folic acid and other dietary supplements on early child development. Matern Child Health J 12, 180-187.

14. Dobo M \& Czeizel AE (1998) Long-term somatic and mental development of children after periconceptional multivitamin supplementation. Eur J Pediatr 157, 719-723.

15. Tamura T, Goldenberg RL, Chapman VR et al. (2005) Folate status of mothers during pregnancy and mental and psychomotor development of their children at five years of age. Pediatrics 116, 703-708.

16. Chatzi L, Plana E, Daraki V et al. (2009) Metabolic syndrome in early pregnancy and risk of preterm birth. Am J Epidemiol 170, 829-836.

17. Koutra K, Chatzi L, Roumeliotaki T et al. (2012) Sociodemographic determinants of infant neurodevelopment at 18 months of age: Mother-Child Cohort (Rhea Study) in Crete, Greece. Infant Behav Dev 35, 48-59.

18. Bayley N (2006) Bayley Scales of Infant and Toddler Development, 3rd ed. [PsychCorp, editor]. San Antonio, TX: Harcourt Assessment Inc.

19. Royston P \& Wright EM (1998) How to construct 'normal ranges' for fetal variables. Ultrasound Obstet Gynecol 11, 30-38. 
20. Joshi S, Rao S, Girigosavi S et al. (2004) Differential effects of fish oil and folic acid supplementation during pregnancy in rats on cognitive performance and serum glucose in their offspring. Nutrition 20, 465-472.

21. Middaugh LD, Grover TA, Blackwell LA et al. (1976) Neurochemical and behavioral effects of diet related perinatal folic acid restriction. Pharmacol Biochem Behav $\mathbf{5}, 129-134$

22. Ferguson SA, Berry KJ, Hansen DK et al. (2005) Behavioral effects of prenatal folate deficiency in mice. Birth Defects Res A Clin Mol Teratol 73, 249-252.

23. Troen AM, Chao WH, Crivello NA et al. (2008) Cognitive impairment in folate-deficient rats corresponds to depleted brain phosphatidylcholine and is prevented by dietary methionine without lowering plasma homocysteine. J Nutr 138, 2502-2509.

24. Kim JM, Lee H \& Chang N (2002) Hyperhomocysteinemia due to short-term folate deprivation is related to electron microscopic changes in the rat brain. J Nutr 132, 3418-3421.

25. Kruman II, Mouton PR, Emokpae R Jr et al. (2005) Folate deficiency inhibits proliferation of adult hippocampal progenitors. Neuroreport 16, 1055-1059.

26. Tamura $\mathrm{T} \&$ \& Picciano MF (2006) Folate and human reproduction. Am J Clin Nutr 83, 993-1016.

27. Bailey LB \& Gregory JF 3rd (1999) Folate metabolism and requirements. J Nutr 129, 779-782.

28. Fernstrom JD (2000) Can nutrient supplements modify brain function? Am J Clin Nutr 71, 6 Suppl., S1669-S1675.

29. Bassett AS, Chow EW, Weksberg R et al. (2002) Schizophrenia and genetics: new insights. Curr Psychiatry Rep $\mathbf{4}$, 307-314.

30. Suzuki MM \& Bird A (2008) DNA methylation landscapes: provocative insights from epigenomics. Nat Rev Genet 9 , 465-476.

31. Singh SM, Murphy B \& O'Reilly RL (2003) Involvement of gene-diet/drug interaction in DNA methylation and its contribution to complex diseases: from cancer to schizophrenia. Clin Genet 64, 451-460.

32. McNulty H \& Scott JM (2008) Intake and status of folate and related B-vitamins: considerations and challenges in achieving optimal status. Br J Nutr 99, Suppl. 3, S48-S54.

33. Petrakos G, Panagopoulos P, Koutras I et al. (2006) A comparison of the dietary and total intake of micronutrients in a group of pregnant Greek women with the Dietary
Reference Intakes. Eur J Obstet Gynecol Reprod Biol 127, 166-171.

34. Timmermans S, Jaddoe VWV, Hofman A et al. (2009) Periconception folic acid supplementation, fetal growth and the risks of low birth weight and preterm birth: the Generation R Study. Br J Nutr 102, 777-785.

35. Pastor-Valero M, Navarrete-Munoz EM, Rebagliato $M$ et al. (2011) Periconceptional folic acid supplementation and anthropometric measures at birth in a cohort of pregnant women in Valencia, Spain. Br J Nutr 105, 1352-1360.

36. Williams LJ, Rasmussen SA, Flores A et al. (2005) Decline in the prevalence of spina bifida and anencephaly by race/ ethnicity: 1995-2002. Pediatrics 116, 580-586.

37. Boulet SL, Yang Q, Mai C et al. (2008) Trends in the postfortification prevalence of spina bifida and anencephaly in the United States. Birth Defects Res A Clin Mol Teratol 82, 527-532.

38. Sweeney MR, Staines A, Daly L et al. (2009) Persistent circulating unmetabolised folic acid in a setting of liberal voluntary folic acid fortification. Implications for further mandatory fortification? BMC Public Health 9, 295.

39. Morris MC, Evans DA, Bienias JL et al. (2005) Dietary folate and vitamin $\mathrm{B}_{12}$ intake and cognitive decline among community-dwelling older persons. Arch Neurol 62, 641-645.

40. Troen AM, Mitchell B, Sorensen B et al. (2006) Unmetabolized folic acid in plasma is associated with reduced natural killer cell cytotoxicity among postmenopausal women. J Nutr 136, 189-194.

41. Cole BF, Baron JA, Sandler RS et al. (2007) Folic acid for the prevention of colorectal adenomas: a randomized clinical trial. JAMA 297, 2351-2359.

42. Yajnik CS, Deshpande SS, Jackson AA et al. (2008) Vitamin B12 and folate concentrations during pregnancy and insulin resistance in the offspring: the Pune Maternal Nutrition Study. Diabetologia 51, 29-38.

43. Lawrance AK, Deng L \& Rozen R (2009) Methylenetetrahydrofolate reductase deficiency and low dietary folate reduce tumorigenesis in Apc $\mathrm{min} /+$ mice. Gut 58, 805-811.

44. Hoyo C, Murtha AP, Schildkraut JM et al. (2011) Folic acid supplementation before and during pregnancy in the Newborn Epigenetics STudy (NEST). BMC Public Health 11, 46 . 